\title{
ETIOLOGY AND SURGICAL OUTCOME OF CHRONIC SUBDURAL HEMATOMA AT TERTIARY CARE HOSPITAL.
}

1. MBBS, MS

Assistant Professor

Department of Neurosurgery

Indus Medical College

Tando Muhammad khan.

2. MBBS, FCPS

Senior Registrar

Department of Medicine

LUMHS.

3. MBBS, MS

Assistant Professor

Department of Neurosurgery

LUMHS.

4. MBBS, FCPS

Fellow, Diabetes,

Endocrinology and Metabolism

Baqai Institute of Diabetology and

Endocrinology Karachi.

5. MBBS, FCPS

Internal Medicine

Senior Registrar

Bhitai Dental and Medical College,

Mirpurkhas

Correspondence Address:

Dr. Hameedullah Khan

Department of Neurosurgery

Indus Medical College

Tando Muhammad khan

drhameedkhan2581@gmail.com

Article received on:

15/04/2019

Accepted for publication:

$31 / 07 / 2019$

\section{INTRODUCTION}

Subdural space is a capillary gap amid the arachnoid mater and dura mater and comprises a little amount of serous fluid that moisturizes smooth opposite surfaces. Bleeding between arachnoid and dura results in subdural hematoma. Conventionally, subdural hematoma may be categorized as sub-acute, acute and the chronic subdural hematoma, purely in terms of time which they take to produce symptoms. Clinically during 72 hours of trauma are usually considered acute. ${ }^{1}$ Post traumatic acute subdural hematoma is one of the unexplained challenges in neurotraumatology. In spite of major development in outcome of the head

\begin{abstract}
Hameedullah Khan', Ihsanullah Rajar' ${ }^{2}$, Abdul Rauf Memon ${ }^{3}$, Nadeem Naeem ${ }^{4}$, Zeeshan UI Haque ${ }^{5}$
\end{abstract}
ABSTRACT... Objectives: To determine etiology and management outcome among patients presenting with chronic subdural hematoma at tertiary care Hospital. Study Design: Cross Sectional. Setting: Department of neurosurgery, Liaquat University Hospital, Hyderabad/ Jamshoro. Period: One year from 2015 to 2016. Material \& Methods: All the patients with diagnosis of unilateral chronic subdural hematoma, and both male and female gender were fuded in this study. CT scan and other relevant laboratory investigations were done. All the were followed at outpatients department for 1-month, 3-months and 3-months, respectively. injury, eleven patients had no obvious cause and one patient had chronic subdural hematoma econdary to over shunting. According to complications; intracerebral bleed was among cases and Pneumocephalus was in $2(6 \%)$ cases, followed by subdural empyema, acute leakage and dysphasia were found in one patient in each case, respectively. Almost every patient recovered and survival rate was $28(93 \%)$, while only two patients died. Conclusion: It was concluded that patients showed best outcome (93\% survival rate) according to Glasgow Outcome Scale, after burr hole evacuation management. Head injury due to road traffic accident was the most common etiology and burr hole evacuation was the best treatment option for Key words: Burr Hole Evacuation, Chronic Subdural Hematoma, Etiology.

Article Citation: Khan H, Rajar I, Memon AR, Naeem N, Zeeshan ul Haque. Etiology and Surgical outcome of chronic Subdural hematoma at Tertiary Care Hospital. Professional Med J 2019; 26(12):2156-2161.

DOI: 10.29309/TPMJ/2019.26.12.3560 hematoma persistently represent $50.0 \%$ to $74.0 \%$ rate of mortality. Related to the lesion incidence, the first computed topography scan associates with poorer outcomes. ${ }^{2,3}$ If symptoms of hematoma emerge within three weeks, it is termed as sub-acute. ${ }^{4}$ In the chronic subdural hematoma (CSDH), symptoms emerge following three weeks of injury. Instead of using a temporal difference between chronic and acute subdural hematoma, a few surgeons explain CSDH as liquid hematoma; and explain acute-subdural hematoma as clotted-hematoma. ${ }^{1,4}$ In the subjects admitted with chronic subdural hematoma (CSDH); a general interval between the diagnosis 
and a known trauma was 4.0-5.0 weeks. ${ }^{1,5} \mathrm{CSDH}$ is a frequent challenging condition in adults with head injury; even in trivial trauma overlooked by the subject. ${ }^{6-9} \mathrm{CSDH}$ is a collection of nearly always dark colored transformed liquid blood associated with a neomembrane located amid arachnoid mater and dura mater. CSDH is an eminent curable disorder among the elderly subjects. ${ }^{5}$ The disease is further frequent in older age because of anatomical causes. The surgery is required in majority of the subjects and outcome is quite good. Chronic subdural hematomas (CSDHs) are in $11.0 \%$ to $35.0 \%$ of patients. In early surgery it becomes evident that removal of only 1 of the 2 hematomas will precipitate expansion of the contra lateral untreated hematoma. If bilateral hematomas exist, they must be treated simultaneously.

The most frequent factor of CSDH is minor head injury which can possibly be overlooked by the subject. Trauma is a significant factor of $\mathrm{CSDH}$. Patients generally become symptomatic several days or week after a minor head injury. ${ }^{6,10}$ Almost $50 \%$ of chronic traumatic subdural collection results into subdural hematoms. Though 40.0$50.0 \%$ of subjects do not have any trauma history ${ }^{11}$ and other $50 \%$ can possibly be considered such as anticoagulant medication, coagulopathy ${ }^{12}$, acetylsalicylic acid ${ }^{13}$, dural sarcomas, metastatic cancers meningiomas, arachnoid cyst and vascular malformations. Chronic subdural hematoma $(\mathrm{CSDH})$ can manifest with different neurological signs and symptoms including seizures, hemiparesis and confusion.

The commonly found symptoms are headache among $81.0 \%$, weakness in $22.0 \%$, vomiting in $30.0 \%$, confusion in $38.0 \%$, variation in consciousness $47.0 \%$, seizures in $9.0 \%$ and visual symptom among $13.0 \%$. Signs can possibly be memory loss among $27.0 \%$, motor weakness among $41.0 \%$, dysphasia in $11.0 \%$, pupalary inequality in $21.0 \% .{ }^{14}$ CT scan is very convenient technique for diagnosis of $\mathrm{CSDH}$. Though; $76.0 \%$ of CSDHs are hypodense on computerized tomography scan. The lesion can possibly also be in mixed density or isodense. $\mathrm{MRI}$ is superior to computerized tomography scan for imaging subdural collections. 4th generation computerized tomography scan cam possibly miss $\mathrm{CSDH} .{ }^{14}$ Treatment for $\mathrm{CSDH}$ is controversial ranging from craniotomy to burr hole irrigation without or with closed drainage system. Decisive treatment of $\mathrm{CSDH}$ is surgical removal of clot, however occasionally when clot is minor it can be treated medically by hydration, Mannitol, steroids and rest. ${ }^{14}$ Majority of patients with $\mathrm{CSDH}$ are effectively treated with external drainage and simple burr hole evacuation. ${ }^{6,7}$ Studies showed controversial findings regarding etiology and treatment outcome. Therefore this study was conducted to determine the etiology and management outcome among patients presenting with chronic subdural hematoma. This study will provide the knowledge regarding etiology and updated treatment outcome.

\section{MATERIAL AND METHODS}

This study was performed at the department of neurosurgery of Liaquat University Hospital, Hyderabad/Jamshoro. Over a period of one year from May 2014 to 2015. All the patients with diagnosis of chronic subdural hematoma, and both male and female gender were included in this study and patients with bilateral haematoma were excluded. CT scan and other relevant laboratory investigations were done. All the patients underwent treatment of burr hole evacuation after an informed consent. All the patients were informed regarding complication of treatment before the surgery. One liter of $5 \%$ D/Water, I/V fluid before and one liter during the operation is supposed to assist in expanding the brain following elimination of the clot. These subjects were mostly operated under general anesthesia. Following general anesthesia practice; patient was suitably placed in supine position on operating table with the head tilted to one side. Site to be operated was always placed upwards.

A vertical incision of 2.5 to $3 \mathrm{~cm}$ was given on affected area where maximum thickness of clot was noted according to CT scan. It was closed after taking the burr hole dura and then a vertical incision was done in the dura, and from this site of incision dark brown fluid rushed out with 
pressure. The first flow was controlled by taking cotton paty at the incision site and the suction of the fluid of clot to avoid the sudden emptying of cavity, which can cause the fresh bleeding from the brain. After that incision size was increased and cruciate incision was made for making the opening of the dura large to flow the clot. After the fluid's flow stopped, irrigation of the cavity was started with the normal saline via burr hole by the disposable $50 \mathrm{ml}$ syringe. Normal saline mixed in the residual clot stated coming out the cavity, and on coming of pure colour normal saline from burr hole irrigation was stopped. A subdural nelaton catheter number 10 was then inserted through a particular incision in the scalp. An edge of the burr hole was nipped to avoid kinking of the subdural drain. Drain was connected with a closed drainage bag. Dura was not closed. Muscle and scalp were stitched in layer over the burr holes. Head sides of the patients were kept 20 degree down for 2448 hours post-operatively. This helped to drain the residual clot in the drain bag and to expand the brain. Patients were kept well hydrated by giving large quantities of oral and I/N fluids. All the patients were given antibiotics pre and postoperatively for 7 days. All the patients underwent CT scan to assess the cavity of hematoma and on stable condition patients were discharged. All the cases were followed by OPD 30 days, $3^{\text {rd }}$ month and $6^{\text {th }}$ month. Outcome of the patients was assessed according to GLASGOW OUTCOME SCALE as showed in table below.

\begin{tabular}{|l|l|}
\hline Classification & \multicolumn{1}{c|}{ Description } \\
\hline Grade 5 & $\begin{array}{l}\text { Good recovery, resumption of normal } \\
\text { life. }\end{array}$ \\
\hline Grade 4 & $\begin{array}{l}\text { Moderate disability, disable but } \\
\text { independent. }\end{array}$ \\
\hline Grade 3 & $\begin{array}{l}\text { Severe disability, dependent for daily } \\
\text { support. }\end{array}$ \\
\hline Grade 2 & $\begin{array}{l}\text { Vegetative state, unresponsive and } \\
\text { speechless. }\end{array}$ \\
\hline Grade 1 & $\begin{array}{l}\text { Death } \\
\text { Glasgow outcome scale }\end{array}$ \\
\hline
\end{tabular}

\section{RESULTS}

Over a period of one year total thirty patients were selected with chronic subdural hematoma $(\mathrm{CSDH})$. 51-60 years and 61-70 years of age groups were most common 11(36\%) and $12(40 \%)$ respectively, followed by $40-50$ years were $4(13 \%)$ and more than 70 years patients were only 3 . There were $25(83 \%)$ males and 5 (17\%) females. Few cases were from Hyderabad city and mostly were from rural areas of Sindh. Most of the cases presented with Hemiparesis, headache and speech disorders. (Table-I)

According to the etiology $16(53.3 \%)$ cases had history of the minor head injury caused by road traffic accident and trivial injuries, such as the fall. Eleven patients were noted without any actual causes. No any case was found with Alcohol abuse history, while evidence of bleeding disorder was in 2 cases. 1 case had $\mathrm{CSDH}$ secondary to over shunting. (Table-II)

Postoperatively, no patients complained of headache, so we achieved $100 \%$ result, Hemiparesis improved in all patients within a week except one patient who was an extensor response preoperatively, become unconscious and died due to RTI. Out of 9 patients having dysphasia 6 patients improved completely and their speech became normal. Dysphasia was improved in 2 patients but not $100 \%$ and one patient did not show any improvement post-operatively. CT scan showed ischemia that might be a reason of dysphasia. Dysphasia improved in $2 \%$ cases. One patient who had seizures preoperatively did not become seizures free until a period of six month follow-ups though frequency of seizures was decreased. One patient developed dysphasia post-operatively. One patient was worsening and become unconscious postoperatively and immediately underwent CT scan which showed penetration of drain catheter in brain matter, and large subdural clot was developed, therefore craniotomy was done to evacuate the clot and patient was improved.

Among two cases pneumocephalus developed, but effect of the mass was not enough, for deterioration so patients were recovered. Total two cases expired, one died after $4^{\text {th }}$ postoperative day due to critical condition of chest at admission and other patients died due to CSF leakage on subdural drain removal and subdural empyema 
development and did not recover even with antibiotics and died on $4^{\text {th }}$ day, surgery was planned but died before start the surgery. Among 10 cases; residual hematoma was developed according to CT scan, but recovered without reopen, because they had no any neurological deficit. Complications can be avoided on careful management. Finally good recovery was observed in 28 patients according to GLASGOW OUTCOME SCALE and they left for home with satisfactory condition. (Table-III and IV)

\begin{tabular}{|l|c|}
\hline \multicolumn{1}{|c|}{ Variables } & Frequency (\%) \\
\hline Gender & \\
Male & $25(83 \%)$ \\
Female & $5(17 \%)$ \\
Total & $30(100.0 \%)$ \\
Age groups & \\
$40-50$ & $4(13 \%)$ \\
$51-60$ & $12(40 \%)$ \\
$61-70$ & $11(36 \%)$ \\
$71-80$ & $2(6 \%)$ \\
$81-90$ & $1(3 \%)$ \\
Total & $30(100.0 \%)$ \\
\hline \multicolumn{2}{|c|}{ Table-I. Demographic characteristics of patients } \\
\multicolumn{2}{|c|}{ Etiology } \\
\hline (n=30) \\
\hline Minor Head Injury & No of Patients \\
\hline Coagulopathy & $16(53.3 \%)$ \\
\hline Post V. P shunt & $2(6.7 \%)$ \\
\hline Unknown & $1(3.3 \%)$ \\
\hline Total & $11(36.7 \%)$ \\
\hline Table-Il. Etiology & $30(100.0 \%)$ \\
\hline
\end{tabular}

Table-II. Etiology of chronic subdural hematoma $(n=30)$

\begin{tabular}{|l|c|}
\hline \multicolumn{1}{|c|}{ Complications } & No of Patients \\
\hline Subdural Empyema & $1(3 \%)$ \\
\hline Penetration of brain by drain catheter & $1(3 \%)$ \\
\hline Intracerebral Bleed & $2(6 \%)$ \\
\hline Acute subdural hematoma & $1(3 \%)$ \\
\hline Pneumocephalus & $2(6 \%)$ \\
\hline Extra dural hematoma & $1(3 \%)$ \\
\hline Dysphasia & $1(3 \%)$ \\
\hline C.S.F leakage complication $\mathbf{n = 3 0}$ & $1(3 \%)$ \\
\hline \multicolumn{1}{|c|}{ Table-III. Cases distribution according to } \\
\hline \multicolumn{1}{|c|}{ Outcome } & No of Patients \\
\hline \multicolumn{2}{|c|}{$28(93 \%)$} \\
\hline Good Recovery & 00 \\
\hline Moderate Disability & 00 \\
\hline Serve Disability & 00 \\
\hline Vegetative State & $2(6 \%)$ \\
\hline Death & \\
\hline
\end{tabular}

Table-IV. Surgical outcome Glasgow outcome scale $\mathrm{n}=\mathbf{3 0}$

\section{DISCUSSION}

This study, regarding the etiology and surgical out come in patients of chronic subdural hematoma $(\mathrm{CSDH})$ through single burr hole drain placement technique, was carried out over a period of one year. During this period thirty cases were operated for CSDH. In this study most of the patients presented with $6^{\text {th }}$ or $7^{\text {th }}$ decades of their lives and twenty five patients $25(83 \%)$ were aged more than 50 years. This is a perfect match with the international study of Miranda LB et $\mathrm{al}^{15}$ conducted at united state. And another study of Kitya $\mathrm{D}$ et $\mathrm{al}{ }^{16}$ reported that males were in majority $72.8 \%$. Similarly a national study of Vash Dev et $\mathrm{al}^{17}$ also found comparable results regarding age. In our study male to female ratio was 6:1 and the ratio also correlated nearly with a large study conducted by Vash Dev et $\mathrm{al}^{17}$, in which males were $63.6 \%$. In another study conducted in department of Neurosurgery, Hayatabad, Peshawar; male to female ratio was $4: 1$, through there was a difference which could be due to over small sample size. ${ }^{18}$ Bankole OB et $a{ }^{19}$ also found similar findings regarding gender as 46 males (83.64\%) and 9 females (16.36\%).

In our study out of 30 patients 17 (56.6\%) had history of head trauma due to RTA. In contrast to our study, Bankole OB et al ${ }^{19}$ reported that 71 $(41.82 \%)$ cases had history of road traffic accident. Huang et al. ${ }^{20}$ conducted study in Taiwan and found traumatic brain injury in $73(74.49 \%)$ of 98 patients. Rovlias et al. ${ }^{21}$ in Brazil found TBI in 503 (51.01\%) out of 986 patients. In these studies traumatic brain injury rate was higher as compare to this study, and this may be due to small sample size of our study. In our study $36.7 \%$ cases had unknown cause, which was similar to the study of Bankole OB et $\mathrm{al}^{19}$, as $22 \%$ cases were presented with unknown causes. The patients with unknown etiology were probably from trivial trauma as none of them was on anticoagulant, antiplatelet aggregation or had coagulopathy. ${ }^{19}$ Some other national and international studies conducted by Mekaj AY et $\mathrm{al}^{22}$ and Kazmi AM et $\mathrm{al}^{23}$, also found comparable findings. In this study according to complications; one case showed subdural Empyema, intracerebral Bleed occurred in 2 cases, Pneumocephalus was among 2 patients, 
extra dural hematoma developed in one case, acute subdural hematoma in one case, C.S.F leakage was found in one case and dysphasia was also found in one case, while overall complication rate was $30 \%$, which is near to the recent study of Rovlias $A$ et $\mathrm{al}^{24}$ which reported a postoperative complications rate of $22.7 \%$. Kitya $\mathrm{D}$ et $\mathrm{al}^{16}$ reported that wound infection developed in four patients, subdural empyema developed in only one patient, and infection rate was $2.4 \%$. Lee $\mathrm{L}$ et $\mathrm{al}^{25}$ showed that surgical complication rate was $11.4 \%$.

In this study surgical outcome was addressed according to Glasgow Outcome Scale, almost all patients recovered and survival rate was $94 \%$, while mortality rate was $6 \%$. In contrast to this study ACHAKZAI NU et $\mathrm{al}^{26}$ reported that 129 (89\%) patients had favorable outcome while $16(11 \%)$ patients had unfavorable outcome. Bankole OB et al ${ }^{19}$ reported that favorable outcome was $94.54 \%$ and it was significantly affected by GCS prior to surgery. Silva et $\mathrm{al}^{27}$ in Brazil found favorable outcome of $82.4 \%$ and their outcome was also affected by GCS. Mulligan $\mathrm{P}$ et $\mathrm{al}^{28}$ reported that $3(7 \%)$ died in the postoperative period. So looking at the rates of complication, it appears high but it may be because of the small sample size and may be because overlooking of minor things pre-operatively. Common complications that we encountered were pneumocephalus, acute subdural hematoma, and subdural emphyema and these can be due to avoiding and correcting the coagulopathy or carefully insertion of catheter and proper post-operative care.

\section{CONCLUSION}

It was concluded that chronic subdural hematoma $(\mathrm{CSDH})$ is a benign lesion, mostly found in the elderly people. Patients showed best outcome of 93\% survival rate according to Glasgow outcome Scale, after burr hole evacuation management. Head injury due to road traffic accident was the most common etiology and burr hole evacuation was the best treatment option for chronic subdural hematoma. CT scan is the best diagnostic choice for chronic subdural hematoma (CSDH). Early diagnostic of CSDH is essential for best outcome with deteriorating the neurological status outcome may become poor.

Copyright@ 31 July, 2019.

\section{REFERENCES}

1. R.A. Beatty. Subdural Hematoma in the elderly: Experience with treatment by trephine craniotomy and not closing the dura or replacing the bone plate. British Journal of Neurosurgery 2011; 13(1): 60-64.

2. F. Servadei, M.T. Nasi, et al. CT prognostic factor in acute subdural hematoma: The value of the (Worst) CT scan. British Journal of Neurosurgery 2000; 14(2): 110-116.

3. W.A. van den Brink, M.Zwieneberg, S.M. Zandee et al. The prognostic importance of the volume of traumatic epidural and subdural hematoma revisited. Acta Neurochirurgica (Wien) (2010) 141: 509-514.

4. Tom Scaletta, M.D. Subdural hematoma. Emedicine free online topic 560.htm. 08/07/2000.

5. G.Stroobandt, P.Fransen, C.Thauvoy, and E.Menard. Pathogenetic factor in chronic subdural hematoma and causes of recurrence after drainage. Acta Neurochirurigica (Wien) (2008) 137:6-14.

6. Mukesh Misra, M.D, Jose L. Salazer, M.D F.A.C.S, and Donna M.Bloom, R.N., B.S.N. Subdural-Peritoneal Shunt: Treatment for bilateral chronic subdural hematoma. Surg Neurol 2007; 46: 378-83.

7. Komiyama, M.D., Toshihiro Yasui, M.D. Katsuhiko Tamura, M.D. et al. Chronic subdural hematoma associated with middle meningeal arteriovenous fistula treated by a combination of embolization and burr hole drainage. Surg Neurol 2009; 42: 316-9.

8. Robert A. Sabo, M.D., William C. Hanigan, M.D., PH.d., and Jean C. Aldag, Ph.D. Chronic subdural hematoma and seizures: The role of prophylactic anticonvulsive medication. Surg Neurol, 2011: 43: 579-82.

9. R.S. Maurice-William. Chronic subdural hematoma: An everyday problem for the neurosurgeon. British Journal of Neurosurgery 1999; 13(6); 547-549.

10. C.K. Park, K.H. Choi, M.C. Kim, J.K. Kang, and C.R. Choi. Spontaneous evolution of posttraumatic subdural hematoma hygroma into chronic subdural hematoma. Acta Neurochirurgica (Wien) (2010) 127:4147.

11. C.Smely, A.Madlinger, and R.Scheremet. Chronic subdural hematoma a comparison of two different treatment modalities. Acta Neurochirurigica (Wien) (2006) 139:818-826. 
12. Jacek Ouschowski. Chronic Subdural Hematoma. Neuro Section G Head Trauma Chapter 112, 545-7

13. S.Spektor, E.Ashkenazi, and Z. Israel. Intracranial hemorrhage from a meningioma in a patient receiving aspirin prophylaxis: A Case Report. Acta Neurochirurgica (Wien) (2007) 134: 51-53.

14. Michael L.J. Apuzzo, Chronic subdural hematoma in adults. Brain Surgery, Complication Avoidance and Management Volume 2, 2005: 1299-1314.

15. Miranda LB, Braxton E, Hobbs J, Quigley MR. Chronic subdural hematoma in the elderly: not a benign disease. Journal of neurosurgery. 2011 Jan 1; 114(1):72-6.

16. Kitya D, Punchak M, Abdelgadir J, Obiga O, Harborne D, Haglund MM. Causes, clinical presentation, management, and outcomes of chronic subdural hematoma at Mbarara Regional Referral Hospital. Neurosurgical focus. 2018 Oct 1; 45(4):E7.

17. Vash Dev, Chohan AM, Umer M. Outcome of BurrHole craniostomy for chronic subdural hematoma. J Liaquat Uni Med Health Sci. 2015; 14(02):68-72.

18. Rehman $R$, Khattak $A$ et al: outcome of chronic subdural hematoma patients treated by two burr hole method: Gomal Journal of Medical Sciences; Julydecember 2010, vol. 8,No: 2: 161-165

19. Bankole OB. Chronic subdural hematoma\&58; Wide dural window and incision of inner membrane. International Journal of Medical Research and Health Sciences. 2016 Jan 1; 5(8):85-92.

20. Huang $\mathrm{Y}-\mathrm{H}$, Yang $\mathrm{K}-\mathrm{Y}$, Lee T-C, Liao C-C. Bilateral chronic subdural hematoma: what is the clinical significance? International Journal of Surgery 2013;11:544-8
21. Silva DO, Matis GK, Costa LF, Kitamura MAP, Carvalhogo EV, Silva M, et al. Chronic subdural hematomas and the elderly: Surgical results from a series of 125 cases: Old "horses" are not to be shot! Surgical Neurology International 2012;3:150

22. Mekaj AY, Morina AA, Mekaj YH, Manxhuka-Kerliu S, Mittari El, Dug SB, et al. Surgical treatment of 137 cases with chronic subdural hematoma at the University clinical center of Kosovo during the period 2008-2012. Journal of Neuroscience Rural Practice 2015;6:186-90

23. Kazmi AM, Khan AA, Rafiq MFA, Sajjad S. Double burrholes for unilateral and bilateral chronic subdural hematomas; experience and outcome. Pakistan Journal of Surgery 2014; 30:315-9

24. Rovlias A, Theodoropoulos S, Papoutsakis D. Chronic subdural hematoma: Surgical management and outcome in 986 cases: A classification and regression tree approach. Surgical neurology international. 2015; $6 ; 127$

25. Lee L, Ker J, Ng HY, Munusamy T, King NK, Kumar D, $\mathrm{Ng} \mathrm{WH}$. Outcomes of chronic subdural hematoma drainage in nonagenarians and centenarians: $A$ multicenter study. Journal of neurosurgery. 2016 Feb $1 ; 124(2): 546-51$.

26. ACHAKZAI NU, Adil I, Khan S. Outcome of surgical management of chronic subdural hematoma. Pakistan Journal of Neurological Surgery. 2018; 30; 22(2):61-6.

27. Silva DO, Matis GK, Costa LF, Kitamura MAP, Carvalhogo EV, Silva M, et al. Chronic subdural hematomas and the elderly: surgical results from a series of 125 cases: Old "horses" are not to be shot! Surgical Neurology International 2012; 3:150

28. Mulligan P, Raore B, Liu S, Olson JJ. Neurological and functional outcomes of subdural hematoma evacuation in patients over $\mathbf{7 0}$ years of age. Journal of neurosciences in rural practice. $2013 \mathrm{Jul} ; 4(3): 250$.

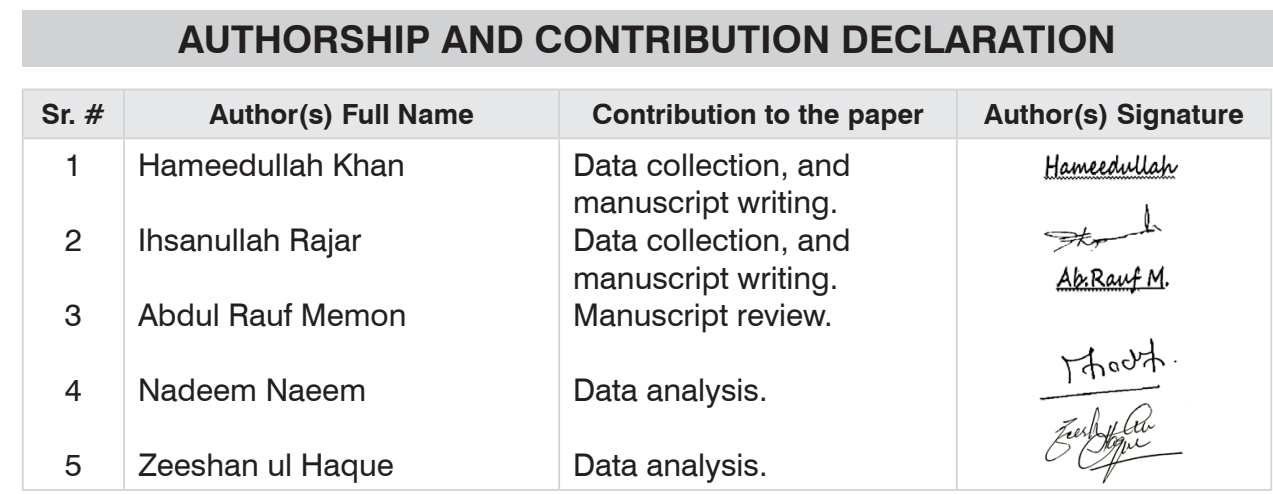

